\title{
Old and new oral anticoagulants for secondary stroke prevention in atrial fibrillation
}

\author{
Tommaso Sacquegna, ${ }^{1}$ Anna Zaniboni, ${ }^{1}$ Andrea Rubboli, ${ }^{2}$ Gaetano Procaccianti, ${ }^{1}$ Michela Crisci, ${ }^{1}$ \\ Fabiola Maioli, ${ }^{3}$ Giorgia Arnone, ${ }^{3}$ Giuseppe Di Pasquale ${ }^{2}$
}

${ }^{1}$ Neurology-Stroke Unit, Institute of Neurological Sciences, Bologna; ${ }^{2}$ Department of Cardiology, Maggiore Hospital, Bologna; ${ }^{3}$ Geriatric and Stroke Unit, Medical Department, Maggiore Hospital, Bologna, Italy

\begin{abstract}
Vitamin K antagonists, such as warfarin, used in oral anticoagulation therapy currently represent the standard drugs for the primary and secondary prevention of stroke in non-valvular atrial fibrillation (AF), with a relative risk reduction close to $70 \%$. Newer oral anticoagulants, such as direct thrombin inhibitors (i.e., dabigatran) and direct factor Xa inhibitors (i.e., apixaban and rivaroxaban) have been recently compared with warfarin in large randomized trials for stroke prevention in $\mathrm{AF}$. The new oral anticoagulants showed, compared with warfarin, no statistically significant difference in the rate of stroke or systemic embolism in secondary prevention (patients with previous transient ischemic attack or stroke) subgroups. With regard to safety, the risk of intracranial bleeding was reduced with new anticoagulants compared with warfarin. Indirect treatment comparisons of clinical trials on secondary prevention cohorts showed no significant difference in efficacy among apixaban, rivaroxaban, and dabigatran; but dabigatran $110 \mathrm{mg}$ was associated with less intracranial bleedings than rivaroxaban.
\end{abstract}

\section{Introduction}

About $20 \%$ of ischemic strokes are cardioembolic and, among the cardioembolic sources, non-valvular atrial fibrillation (NVAF) represents the most frequent abnormality. Moreover, in patients with cryptogenic stroke, NVAF, more often in the paroxysmal form, may be detected in a significant number of cases by means of prolonged electrocardiogram (ECG) monitoring or implanted loop recorder.

The mean stroke rate in NVAF is $4.5 \%$ per year, as reported in the placebo-treated groups of primary prevention studies, ${ }^{1}$ but this risk varies 20 -fold depending on patient's age and other clinical features. ${ }^{2}$

Correspondence: Anna Zaniboni, Neurology-Stroke Unit, IRCCS - Institute of Neurological Sciences, Maggiore Hospital, Largo Nigrisoli 2, 40133 Bologna, Italy.

Tel.: +39.051.64788889.

E-mail: a.zaniboni@ausl.bo.it

Key words: Secondary prevention of stroke; warfarin; apixaban; rivaroxaban; dabigatran; atrial fibrillation.

Received for publication: 1 March 2014.

Revision received: 6 August 2014.

Accepted for publication: 28 August 2014.

This work is licensed under a Creative Commons Attribution NonCommercial 3.0 License (CC BY-NC 3.0).

CCopyright T. Sacquegna et al., 2015

Licensee PAGEPress, Italy

Italian Journal of Medicine 2015; 9:314-322

doi:10.4081/itjm.2015.468
Prior stroke or transient ischemic attack (TIA) is one of the most important risk factors ${ }^{3}$ and the annual stroke recurrence rate after stroke/TIA is $12 \%$ in NVFA patients without antithrombotic treatment. ${ }^{4}$

Although stroke guidelines ${ }^{5}$ recommend oral anticoagulation (OAC) with vitamin K antagonists (VKAs) in the secondary stroke prevention of NVAF patients, this therapy is still underused because of concerns about the increased risk of extra- or intracranial hemorrhages and the need for careful monitoring of the treatment.

Therefore the new non-VKA oral anticoagulants (i.e., factor Xa-inhibitors and direct thrombin inhibitors), which seem to overcome the drawbacks of VKAs and to improve patient management, represent a great opportunity.

The objective of the present narrative review is to analyze the efficacy and safety of old and new OAC in the secondary prevention of stroke related to NVAF.

We performed a literature search of published studies from the Cochrane library, Medline and from reference lists of relevant articles on anticoagulant therapy in AF.

\section{Warfarin for secondary stroke prevention related to non-valvular atrial fibrillation}

\section{Adjusted-dose warfarin compared with placebo}

The Cochrane review (2004) ${ }^{6}$ reports two trials of secondary stroke prevention. The combination of their results shows that warfarin reduces the risk of recurrent stroke by $64 \%$ and increases the risk of major extracranial hemorrhages by 4-fold, but not the risk of intracranial bleeds. 
In the meta-analysis by Hart et al. of 6 randomized trials (2007), ${ }^{7} 20 \%$ of patients had had previous stroke or TIA. Warfarin reduces the risk of recurrent stroke by about two thirds compared with placebo. With warfarin there is a non-significant increase in major bleeds ( $2.8 \%$ on warfarin $v s \quad 0.7 \%$ on placebo).

The main study is the European atrial fibrillation trial (EAFT, 1993) $)^{5}$ which shows that warfarin [target international normalized ratio (INR 2.5-4.0)] reduces the absolute risk (AR) of recurrent stroke by $8 \%$ per year (stroke rate on warfarin $4 \%$ vs $12 \%$ on placebo), therefore 80 strokes are prevented per 1000 patients treated.

\section{Adjusted-dose warfarin compared with antiplatelet agents}

The Cochrane review (2004) ${ }^{8}$ reports two trials of secondary stroke prevention in which warfarin was compared with antiplatelet drugs.

In the first (EAFT, 1993), ${ }^{4}$ warfarin (target INR $2.5-4)$ has been compared with aspirin $(300 \mathrm{mg} /$ day) with a follow-up of 2.3 years. In this study the AR for all recurrent strokes was reduced by $6 \%$ with warfarin (stroke rate on warfarin $4 \%$ vs $10 \%$ on aspirin), therefore resulting in 60 fewer recurrent strokes per year per 1000 patients treated.

Major extracranial bleedings were more frequent with warfarin $(2.8 \%$ per year) than with aspirin $(0.9 \%$ per year).

The second study is the Studio italiano fibrillazione atriale (SIFA, 1997) ${ }^{9}$ in which warfarin (target INR 2.0-3.5) has been compared with indobufene (100-200 mg/day) with a follow-up of 1 year. With warfarin there was a not statistically significant AR reduction of $1 \%$.

In the meta-analysis by Hart et al. (2007) ${ }^{7}$ of 12 trials, which compared warfarin with antiplatelet therapy, $24 \%$ of patients had had previous stroke or TIA. Warfarin reduces the risk of recurrent stroke by about $40 \%$ compared with antiplatelet agents.

Among the 12 trials, the ACTIVE-W (atrial fibrillation clopidogrel trial with irbersartan for prevention of vascular events) $(2006)^{10}$ has shown that warfarin (target INR 2.0-3.0) is approximately $40 \%$ more efficacious than the combination of aspirin (75-100 $\mathrm{mg}$ /day) with clopidogrel (75 mg per day) $(\mathrm{C}+\mathrm{A})$.

Among patients with prior stroke or TIA $(15 \% \mathrm{sec}-$ ondary prevention cohort of 6706 patients), the AR reduction of stroke with warfarin was $3.23 \%$ (stroke rate on warfarin $2.99 \%$ vs $6.22 \%$ on $\mathrm{C}+\mathrm{A}$ ).

Major bleedings occurred with a similar annual rate $(2.75 \%$ on warfarin versus $2.63 \%$ on $\mathrm{C}+\mathrm{A})$.

The more recent Birmingham atrial fibrillation treatment of the aged study (BAFTA, 2007) ${ }^{11}$ compared warfarin (target INR 2-3) with aspirin (75 $\mathrm{mg} /$ day). $13 \%$ of 973 patients had a history of stroke or TIA (secondary stroke prevention cohort). The in- cidence of recurrent stroke was $3.1 \%$ on warfarin and $8.0 \%$ on aspirin, that is an $\mathrm{AR}$ reduction of $5 \%$, which represents 50 fewer recurrent strokes per year per 1000 patients treated.

\section{Comments on vitamin $K$ antagonists therapy}

OAC therapy with VKAs is the mainstay treatment for secondary stroke prevention in NVAF patients with an AR reduction of $8 \% v s$ placebo, of 5-6\% vs aspirin, and of $3 \% v s$ dual antiplatelet therapy.

A decrease in the stroke rate over the years has been observed in patients treated with warfarin. This might be due to improved identification and treatment of vascular risk factors, differences in INR control, or differences in the populations of patients.

The disadvantages of VKAs are well known: narrow therapeutic window (INR 2-3), variability in dose-response, slow onset and offset of action, interactions with many drugs and foods rich in vitamin $\mathrm{K}$. The low therapeutic index needs careful monitoring because an INR of 1.7 doubles the risk of ischemic stroke and the increase in bleeding becomes exponential for INR values $>4.5 .^{12}$

The fear of an intracranial hemorrhage or major bleeds, above all in elderly patients, and the concerns about poor patient compliance restricts more widespread use of warfarin therapy in clinical practice despite its recognized efficacy in stroke prevention.

It is estimated that approximately $50 \%$ of appropriate AF patients do not receive warfarin, and that $25 \%$ of patients who begin taking warfarin quit during the first year. ${ }^{13}$

In a recent Italian study of 7148 patients with $\mathrm{AF}$ admitted in cardiology and internal medicine hospital centers, OAC was prescribed in $55 \%$ of patients with NVAF ( $64 \%$ of cardiology patients and $46 \%$ of internal medicine patients). ${ }^{14}$

Furthermore, in real practice patients spend 30\% to $50 \%$ of the treatment time outside the therapeutic range. ${ }^{15}$

The annual incidence, during VKA therapy, is 2$5 \%$ for major bleeding, $0.5-1 \%$ for fatal bleeding, and $0.2-0.4 \%$ for intracranial hemorrhages $(\mathrm{ICH})$, varying with intensity of anticoagulation and age. ${ }^{16}$

In the BAFTA trial ${ }^{11}$ (patients aged $\geq 75$ years), the incidence of major extracranial hemorrhages was lower and no more hazardous than with aspirin $(1.9 \%$ vs $2.0 \%$ per year). In this study, the annual risk of major hemorrhages rose with age both with warfarin and aspirin with an incidence of 3\% in people aged $\geq 85$ years.

A meta-analysis of patients aged $\geq 75$ years showed that OAC therapy was more effective than aspirin for secondary stroke prevention (the annual rate of ischemic stroke was $4 \%$ for OAC and $10 \%$ for aspirin), but at the cost of higher risk of major bleedings ( 9 
more major bleeds per 1000 patients treated per year). ${ }^{17}$

In a prospective study on very old patients $(\geq 80$ years of age) on VKA treatment for AF treated in experienced centers, Poli et al. ${ }^{18}$ found a low rate of bleedings ( 1.73 per 100 patients/year), explained at least in part by the good quality of the INR control.

Agarwal et al. ${ }^{19}$ analyzing randomized controlled trials (RCTs) of the last ten years, found that the incidence of stroke in patients with NVAF taking warfarin was $1.66 \%$ per year and the risk increased with progressively increasing $\mathrm{CHADS}_{2}$ score in patients aged $\geq 75$ years, in female patients and in patients with previous stroke or TIA. The risk of major bleeding varied from $1.40 \%$ to $3.4 \%$ per year and the risk of intracranial hemorrhage from $0.33 \%$ to $0.80 \%$ per year.

The risk of intracranial bleeding in real practice may be higher as in the RCT there is an underrepresentation of older patients who have the highest frequency of leukoaraiosis and amyloid angiopathy increasing the risk of $\mathrm{ICH} .{ }^{20}$

\section{New oral anticoagulants}

The new oral anticoagulants (NOAC) include direct thrombin inhibitors (dabigatran) and factor $\mathrm{Xa}$ antagonists (rivaroxaban, apixaban).

These agents can be given in fixed doses, do not require regular coagulation monitoring, have more rapid onset and offset and have few clinically relevant drug-drug interactions.

\section{Dabigatran for secondary stroke prevention related to non-valvular atrial fibrillation}

Dabigatranetexilate, a prodrug of active dabigatran, is rapidly absorbed, achieving peak plasma concentration $1.5 \mathrm{~h}$ after oral ingestion with an elimination half-life of 12 to $17 \mathrm{~h}$. After oral administration, it is rapidly hydrolyzed by esterases in plasma and liver to activate dabigatran through a mechanism that is independent from the cytochrome $\mathrm{p} 450$ pathway. Dabigatran elimination occurs up to $80 \%$ by renal excretion and blood levels of the drug are influenced by renal function. Therefore patients with impaired renal function and low body weight may have a higher risk of bleeding. The risk of hemorrhage is increased also by dabigatran'sinteraction with p-glycoprotein inhibitors including verapamil, amiodarone, dronedarone and quinidine, which raise dabigatran serum concentration considerably. Plasma dabigatran levels fall below the therapeutic threshold $15 \mathrm{~h}$ after the administration of the final dose in patients without significant renal impairment. ${ }^{21}$

The Randomized evaluation of long-term anticoagulant therapy $(R E-L Y)$ trial (2009) ${ }^{22}$ randomized 18,113 patients with non-NVAF and at least 1 risk factor for stroke to dabigatran $110 \mathrm{mg}$ or $150 \mathrm{mg}$ twice a day or warfarin (INR, 2 to 3 ), for approximately 2 years. Patients who had a creatinine clearance of less than $30 \mathrm{~mL} / \mathrm{min}$ or liver disease were excluded from RE-LY.

Diener et al. ${ }^{23}$ investigated the efficacy and safety of dabigatran $(110 \mathrm{mg}$ and $150 \mathrm{mg}$ twice a day vs warfarin) on secondary stroke prevention in a predefined subgroup analysis of RE-LY study (20\% of patients in the RE-LY study had had TIA or stroke at least 2 weeks before the randomization).

The study showed that (Table 1): i) the incidence of stroke or systemic embolism was not significantly reduced with $110 \mathrm{mg}$ and $150 \mathrm{mg}$ of dabigatran compared with warfarin; ii) there was a significant reduction in hemorrhagic stroke with $110 \mathrm{mg}$ and $150 \mathrm{mg}$ of dabigatran compared with warfarin; iii) there was a significant reduction in the rates of vascular death and all-cause mortality with dabigatran $110 \mathrm{mg}$, but not with dabigatran $150 \mathrm{mg}$, compared with warfarin; iv) dabigatran $110 \mathrm{mg}$, but not $150 \mathrm{mg}$, significantly reduced the risk of major bleeding compared with warfarin; v) the rate of intracranial hemorrhage was reduced significantly with $110 \mathrm{mg}$ and $150 \mathrm{mg}$ of dabigatran compared with warfarin; vi) gastrointestinal bleeding was significantly increased with $150 \mathrm{mg}$ of dabigatran compared with warfarin; while the risk was similar between $110 \mathrm{mg}$ of dabigatran and warfarin. ${ }^{23}$

Table 1. Effects of dabigatran and warfarin on the incidence of stroke or systemic embolism and major bleeding (expressed as percent per year) in RE-LY patients with previous stroke or transient ischemic attack.

\begin{tabular}{|c|c|c|c|c|c|}
\hline \multirow[t]{2}{*}{$\beta$} & \multicolumn{2}{|c|}{ Dabigatran 110 mg } & \multirow{2}{*}{$\begin{array}{l}\text { Warfarin } \\
\% \text { per year }\end{array}$} & \multicolumn{2}{|c|}{ Dabigatran $150 \mathrm{mg}$} \\
\hline & $\%$ per year & ARR & & $\%$ per year & ARR \\
\hline All cases of stroke or systemic embolism & 2.32 & 0.46 & 2.78 & 2.07 & 0.71 \\
\hline Hemorrhagic stroke & 0.08 & 0.69 & 0.77 & 0.20 & 0.57 \\
\hline Vascular death & 1.90 & 1.10 & 3.00 & 2.97 & 0.03 \\
\hline Major bleeding & 2.74 & 1.41 & 4.15 & 4.15 & 0 \\
\hline Intracranial bleeding & 0.25 & 1.03 & 1.28 & 0.53 & 0.75 \\
\hline Gastrointestinal bleeding & 1.39 & 0.02 & 1.41 & 2.32 & $0.91 *$ \\
\hline
\end{tabular}

ARR, absolute risk reduction. *Absolute risk increase. Data from Diener et al., 2010. ${ }^{23}$ 


\section{Comments on dabigatran therapy}

Overall, in patients with previous stroke or TIA, both $110 \mathrm{mg}$ and $150 \mathrm{mg}$ twice daily of dabigatran are similar to or more efficacious than warfarin, even though the difference is not statistically significant, with regard to the prevention of stroke and systemic embolism (approximately 5-7 fewer events/1000 patients/year), with a greater decrease in hemorrhagic stroke than in ischemic or unknown stroke. The dose of $110 \mathrm{mg}$ reduces the risk of intracranial bleeding (approximately 10 fewer events/1000 patients/year) and of major bleeding, with a net clinical benefit when all vascular and bleeding events are combined. The dose of $150 \mathrm{mg}$ also reduces the rate of intracranial bleeding (approximately 8 fewer events/1000 patients/ year), but increases significantly gastrointestinal bleedings (excess of 9 events/1000 patients/year).

Wallentin et al..$^{24}$ analyzed the outcomes of the RELY Study in relation to the time in therapeutic range (TTR) of the warfarin population. Overall, patients on warfarin spent $64 \%$ of the time in the therapeutic range. They found that the rate of intracranial bleeding is lower with both doses of dabigatran compared to warfarin across all INR control ranges.

Eikelboom et al..$^{25}$ analyzed, in the RE-LY Study, the risks and benefits of dabigatran versus warfarin in older patients. The risk of bleeding increased with increasing age and with decreasing creatinine clearance. In patients aged $>75$ the risk of major bleeding with both doses of dabigatran was similar or higher compared with warfarin, whereas the risk of intracranial bleeding was lower, irrespective of age, with both doses of dabigatran compared with warfarin.

A recent reanalysis of intracranial bleeding in the RE-LY study confirmed lower rates of intracerebral hemorrhage in patients assigned to both doses of dabigatran than in warfarin patients. ${ }^{26}$

In the event of bleeding or other situations, the increase in activated partial thromboplastin time, prothrombin time and thrombin time (TT) can provide an approximation of excessive anticoagulant activity, while the INR test is insensitive to dabigatran. For a quantitative measurement of dabigatran plasma concentrations, only the dabigatran calibrated Hemoclot thrombin inhibitor assay (a diluted TT) is available. ${ }^{27}$

As there is no specific antidote, the event of major hemorrhage should be treated by discontinuation of the drug, induction of diuresis and, as in VKA-associated bleeding, the administration of prothrombin complex concentrate. In the murine model of dabigatran-associated intracerebral hemorrhage, prothrombin complex concentrate reduced hematoma size. ${ }^{28}$

The low plasma protein binding of dabigatran $(<35 \%)$ suggests that dialysis may be useful although there is only limited experience with this approach. ${ }^{29}$

There is ongoing controversy as to whether throm- bin inhibitors raise the risk of myocardial infarction. The main RE-LY study ${ }^{22}$ showed a small increase in the rate of myocardial infarction with dabigatran (approximately an excess of 2 events/1000 patients/year). A recent reanalysis of patients' ECGs, however, identified 28 silent myocardial infarctions (distributed over the three groups), which were not included in the original analysis. When included in the data set, the numerical increase in myocardial infarction was no longer significant. ${ }^{30}$

Also Hohnloser et al. ${ }^{31}$ described, in a sub-group analysis of the RE-LY trial, a non-significant increase in myocardial infarction with dabigatran compared to warfarin, but other myocardial ischemic events, including unstable angina, need for coronary revascularization, cardiac arrest, or cardiac death, were not increased.

The meta-analysis by Uchino and Hernandez of 7 randomized trials ${ }^{32}$ confirmed a 33\% higher relative risk of miocardial infarction in patients taking dabigatran (but with a very small absolute risk increase, i.e., $0.27 \%$ per year).

Long-term data, after 2.3 years of additional treatment after the RE-LY trial, showed low and unchanged rates of stroke or systemic embolism on dabigatran $110 \mathrm{mg}$ and $150 \mathrm{mg}$, including a low rate of hemorrhagic stroke. A higher rate of major bleeding was observed with dabigatran $150 \mathrm{mg}$ compared with dabigatran $110 \mathrm{mg}$ (RELY-ABLE, 2013). ${ }^{33}$

The Danish cohort study, ${ }^{34}$ after dabigatran postapproval availability, confirmed in an everyday clinical practice population markedly lower intracranial bleeding rate with both doses of $110 \mathrm{mg}$ and $150 \mathrm{mg}$ of dabigatran compared with warfarin, and lower gastrointestinal bleeding only with dabigatran $110 \mathrm{mg}$.

\section{Apixaban for secondary stroke prevention related to non-valvular atrial fibrillation}

Apixaban, a direct factor $\mathrm{Xa}$ inhibitor, is rapidly absorbed with a peak plasma concentration of $3 \mathrm{~h}$ and a half-life of 8 to 15 h. $25 \%$ of elimination is via renal excretion. Apixaban interacts only with drugs that are potent cytochrome CYP3A4 inducers (phenytoin or carbamazepine) or inhibitors (ketokonazole). ${ }^{35}$

The Apixaban versus acetylsalicylic acid [ASA] to prevent stroke in atrial fibrillation patients who have failed or are unsuitable for vitamin $K$ antagonist treatment (AVERROES) trial (2011) ${ }^{36}$ was designed to determine the efficacy and safety of apixaban versus aspirin. Apixaban, at a fixed dose of $5 \mathrm{mg}$ twice a day (or reduced dose of $2.5 \mathrm{mg}$ twice a day in patients with a predefined risk profile), was compared with aspirin at a dose of 81 to $324 \mathrm{mg} /$ day, Diener et al..$^{37}$ investigated the efficacy and the safety of apixaban, compared with aspirin, on secondary stroke prevention in 764 patients with AF and previous stroke or TIA (pre- 
specified subgroup analysis of the AVERROES trial).

The main results were the following (Table 2): i) the incidence of all cases of stroke or systemic embolism was significantly reduced in the apixaban group compared with the aspirin group; ii) there was a non-significant reduction in the rate of vascular death and all-cause mortality with apixaban compared with aspirin; iii) the rate of all major bleedings was not significantly increased with apixaban; iv) the risk of gastrointestinal bleeding and intracranial hemorrhage was not statistically different between apixaban and aspirin.

In the Apixaban for reduction in stroke and other thromboembolic events in atrial fibrillation (ARISTOTLE) trial (2011), ${ }^{38}$ apixaban at a dose of $5 \mathrm{mg}$ twice daily (or a predefined reduced dose), was compared with warfarin (INR 2.0 to 3.0).

Easton et al. ${ }^{39}$ investigated the efficacy and the safety of apixaban, compared with warfarin, in secondary stroke prevention, in 3436 patients with atrial fibrillation and previous stroke or TIA more than 30 days before random allocation (only 234 patients were included between 8 and 30 days after stroke) (prespecified subgroup analysis of the ARISTOTLE trial).

The main results were the following (Table 3): i) the incidence of all cases of stroke or systemic embolism was not significantly reduced in the apixaban group compared with warfarin group; ii) there was a significant reduction in hemorrhagic stroke in the apixaban group compared with warfarin; iii) the vascular death from any cause was similar in both groups; iv) the rate of intracranial bleeding was reduced significantly with apixaban compared with warfarin; v) the rate of gastrointestinal bleeding was not significantly different between apixaban and warfarin. ${ }^{39}$

\section{Comments on apixaban therapy}

In secondary stroke prevention in AF patients, apixaban $5 \mathrm{mg}$ twice a day demonstrated superior efficacy over aspirin (approximately 65 fewer events/1000 patients/year) with a greater risk of major bleeding (excess of 10 events/1000 patients/year). ${ }^{37}$

Compared with warfarin, apixaban reduced the risk of stroke or systemic embolism (8 fewer events/1000 patients/year, mainly less hemorrhagic stroke) and caused less bleeding (approximately 10 fewer major bleedings/1000 patients/year) with a more substantial reduction in intracranial bleeding and a trend toward lower risk for gastrointestinal bleeding. ${ }^{38}$

Table 2. Effects of apixaban and aspirin on the incidence of stroke or systemic embolism and major bleeding (expressed as percent per year) in AVERROES patients with previous stroke or transient ischemic attack.

\begin{tabular}{lccc}
\hline & $\begin{array}{c}\text { Apixaban } \\
\text { \% per year }\end{array}$ & $\begin{array}{c}\text { Aspirin } \\
\text { \% per year }\end{array}$ & ARR \\
\hline All cases of stroke or systemic embolism & 2.39 & 9.16 & 6.77 \\
\hline Hemorrhagic stroke & 0.27 & 1.07 & 0.80 \\
\hline All-cause death & 5.78 & 7.92 & 1.14 \\
\hline Major bleeding & 4.10 & 2.89 & $1.21^{*}$ \\
\hline Intracranial bleeding & 1.17 & 1.56 & 0.39 \\
\hline Gastrointestinal bleeding & 0.84 & 1.31 & 0.47 \\
\hline
\end{tabular}

ARR, absolute risk reduction. *Absolute risk increase. Data from Diener et al., 2012. ${ }^{37}$

Table 3. Effects of apixaban and warfarin on the incidence of stroke or systemic embolism and major bleeding (expressed as percent per year) in ARISTOTLE patients with previous stroke or transient ischemic attack.

\begin{tabular}{lccc}
\hline & $\begin{array}{c}\text { Apixaban } \\
\text { \% per year }\end{array}$ & $\begin{array}{c}\text { Warfarin } \\
\text { \% per year }\end{array}$ & ARR \\
\hline All cases of stroke or systemic embolism & 2.46 & 3.24 & 0.78 \\
\hline Hemorrhagic stroke & 0.40 & 1.00 & 0.60 \\
\hline Vascular death & 2.35 & 2.41 & 0.06 \\
\hline Major bleeding & 2.84 & 3.91 & 1.07 \\
\hline Intracranial bleeding & 0.55 & 1.49 & 0.94 \\
\hline Gastrointestinal bleeding & 0.66 & 0.80 & 0.14 \\
\hline
\end{tabular}

ARR, absolute risk reduction. Data from Easton et al., 2012.39 


\section{Rivaroxaban for secondary stroke prevention related to non-valvular atrial fibrillation}

Rivaroxaban, a direct factor Xa inhibitor, has a rapid onset of action with a time to peak of 3 hours and a half-life of 6 to $10 \mathrm{~h}$. The drug is eliminated up to two thirds by the kidneys. Rivaroxaban has few interactions with other drugs with the exception of drugs that are potent cytochrome CYP3A4 inducers (phenytoin or carbamazepine) or inhibitors (ketokonazole). ${ }^{40}$

The Rivaroxaban once daily oral direct factor Xa inhibition compared with vitamin $K$ antagonist for prevention of stroke and embolism trial in atrial fibrillation (ROCKET AF) trial ${ }^{41}$ compared rivaroxaban $20 \mathrm{mg}$ once daily (or a reduced dose of $15 \mathrm{mg}$ in patients with a creatinine clearance of $30-49 \mathrm{~mL} / \mathrm{min}$ ) with adjusted-dose warfarin (INR 2.0-3.0) in more than 14,000 high risk patients with NVAF (with a $\mathrm{CHADS}_{2}$ score $\geq 2$ and half with prior stroke). Hankey et al..$^{42}$ investigated the efficacy and safety of rivaroxaban compared with warfarin on secondary stroke prevention in 7468 patients with $\mathrm{AF}$ and previous stroke or TIA (pre-specified subgroup analysis of the ROCKET AF trial). The study included patients 14 days after acute stroke and 3 months after severe disabling stroke.

The main results were the following (Table 4): i) the incidence of all cases of stroke or systemic embolism was not significantly different between the rivaroxaban and warfarin group; ii) the rate of hemorrhagic stroke and vascular death was not different between the two groups; iii) the incidence of major bleeding was not different, but less fatal bleeding occurred with rivaroxaban; iv) the rate of intracranial hemorrhage was not significantly reduced with rivaroxaban compared with warfarin. ${ }^{42}$

\section{Comments on rivaroxaban therapy}

Rivaroxaban in secondary stroke prevention related to $\mathrm{AF}$ was not inferior to warfarin for the prevention of stroke and systemic embolism, with a trend toward less hemorrhagic stroke (warfarin patients were in therapeutic range of INR only $58 \%$ of the time, less than in other trials).

With regard to safety, rivaroxaban has a comparable risk for major bleeding and a non-significant reduction of intracranial hemorrhage. ${ }^{42}$

\section{Comments on the safety profile of new oral anticoagulation}

All three new non-VKA anticoagulants are equivalent or even superior to warfarin for secondary stroke prevention related to $\mathrm{AF}$, but the mean time in therapeutic range for warfarin treatment was $64 \%, 62 \%$ and $55 \%$ respectively in the three main trials of new anticoagulants, and the difference in relative efficacy versus warfarin, at least for dabigatran $110 \mathrm{mg}$ and for rivaroxaban, was not significant when the time in therapeutic INR range increased over $65 \%$.

With regard to safety, the new anticoagulants are associated with a decreased risk for intracranial bleeding (7-10 fewer hemorrhagic events/1000 patients/ year for dabigatran and apixaban, and non-significant difference for rivaroxaban), whereas the risk of intracranial bleeding related to warfarin therapy is high even with excellent INR control. ${ }^{24}$

The risk of major bleeding is significantly reduced by dabigatran $110 \mathrm{mg}$ (but not by the $150 \mathrm{mg}$ dose) compared to warfarin. Apixaban shows a trend toward lower risk for gastrointestinal bleeding.

Banerjee et al. ${ }^{43}$ showed that all three new anticoagulants appear superior to warfarin for the net clinical benefit (balancing ischemic stroke against intracranial hemorrhage) when risk of stroke and bleeding are both high as in secondary stroke prevention.

The meta-analysis of Ntaios et al..$^{44}$ of all three studies on new non-VKA anticoagulants in patients with $\mathrm{AF}$ and previous stroke or TIA showed a $50 \%$ significant reduction of hemorrhagic stroke with NOAC when compared with warfarin. With regard to safety, the non-VKAs were also associated with a significant reduction in intracranial bleedings compared with warfarin, and a trend of more gastrointestinal bleedings mainly due to high-dose dabigatran.

Schneeweiss et al ${ }^{45}$ by means of an adjusted indi-

Table 4. Effects of rivaroxaban and warfarin on the incidence of stroke or systemic embolism and major bleeding (expressed as percent per year) in ROCKET AF patients with previous stroke or transient ischemic attack.

\begin{tabular}{lccc}
\hline & $\begin{array}{c}\text { Rivaroxaban } \\
\text { \% per year }\end{array}$ & $\begin{array}{c}\text { Warfarin } \\
\text { \% per year }\end{array}$ & ARR \\
\hline All cases of stroke or systemic embolism & 2.79 & 2.96 & 0.17 \\
\hline Hemorrhagic stroke & 0.34 & 0.46 & 0.12 \\
\hline Vascular death & 2.93 & 3.00 & 0.07 \\
\hline Major bleeding & 3.13 & 3.22 & 0.09 \\
\hline Intracranial bleeding & 0.59 & 0.80 & 0.21 \\
\hline
\end{tabular}

ARR, absolute risk reduction. Data from Hankey et al., 2012.42 
rect comparison, found that apixaban had a significantly lower risk of major bleeding compared with dabigatran $150 \mathrm{mg}$ or rivaroxaban among patients with $\mathrm{CHADS}_{2} \geq 3$.

An indirect comparison analysis published by Rasmussen et $a l .{ }^{46}$ showed that, for secondary prevention, apixaban, rivaroxaban, anddabigatran had broadly similar efficacy for the main endpoints. Less hemorrhagic stroke, vascular death, major bleeding, and intracranial bleeding occurred with dabigatran $110 \mathrm{mg}$ twice a day than with rivaroxaban.

However, indirect comparison can be exposed to potential flaws and only a direct head-to-head comparison trial would allow drawing valid conclusions.

Overall, the three new anticoagulants have good efficacy and safety profiles without the need for anticoagulation monitoring; therefore they offer a good therapeutic option especially for patients with NVAF and previous stroke or TIA. In fact, we know that previous stroke/TIA is one of the most important risk factors for anticoagulation-associated intracranial bleeding, ${ }^{3,4}$ therefore this favorable safety profile of the new anticoagulants can have a major impact on clinical treatment of patients with previous stroke/TIA and AF. In these patients the net clinical benefit of NOAC is likely to be greater because of less intracranial bleeding.

Also the NOAC edoxaban (a direct acting oral factor Xa inhibition) showed a significant reduction in hemorrhagic stroke and other subtypes of intracranial bleeding compared with warfarin. ${ }^{47}$

The last comprehensive meta-analysis of all four NOAC recently published by Ruff et al ${ }^{48}$ confirmed that overall intracranial bleeding was reduced by half with NOAC compared with warfarin.

The lower risk of intracranial bleeding with NOAC compared with warfarin might be related to the different effect on blood coagulation. The new OAC inhibit only one coagulation factor whereas warfarin affects the activity of factor II, VII, IX, and X in plasma and interferes with the formation of tissue factor- $\mathrm{VII}_{\mathrm{a}}$ complex particularly abundant in the brain. ${ }^{25}$

Even if NOAC do not have specific reversal agents, there is no evidence that major bleeding associated with NOAC has more serious clinical consequences than warfarin-associated bleeding. ${ }^{26,34,48}$

The management of patients on NOAC suffering from major bleeding should include the same interventions used with patients on warfarin.

The development of specific antidotes capable of neutralizing NOAC (i.e., the recent monoclonal antibody idarucizumab for dabigatran) will offer an important treatment option.

\section{References}

1. Atrial Fibrillation Investigators. Risk factors for stroke and efficiency of antithrombotic therapy in atrial fibril- lation: analysys of pooled data from five randomized controlled trials. Arch Intern Med 1994;154:1449-57.

2. The Stroke Risk in Atrial Fibrillation Working Group. Indipendent predictors of stroke in patients with atrial fibrillation: a systematic review. Neurology 2007;69: 546-54.

3. Lip GYH, Nieuwlaat R, Pisters R, et al. Refining clinical risk stratification for predicting stroke and thromboembolism in atrial fibrillation using a novel risk factorbased approach: the Euro Heart Survey on Atrial Fibrillation. Chest 2010;137:263-72.

4. EAFT (European Atrial Fibrillation Trial) Study Group. Secondary prevention in non-rheumatic atrial fibrillation after transient ischemic attack or minor stroke. Lancet 1993;342:1255-62.

5. Camm AJ, Kirchof P, Lip GYH, et al. Task Force for the Management of Atrial Fibrillation of the European Society of Cardiology (ESC). Guidelines for the management of atrial fibrillation. Eur Heart J 2010;31:2369-429.

6. Saxena R, Koudstaal PJ. Anticoagulants for preventing stroke in patients with nonrheumatic atrial fibrillation and a history of stroke or transient ischaemic attack. Cochrane Database Syst Rev 2004;(2):CD000185.

7. Hart RG, Pearce LA, Aquilar MI. Meta-analysis: antithrombotic therapy to prevent stroke in patients who have nonvalvular atrial fibrillation. Ann Int Med 2007;146: 857-67.

8. Saxena R, Koudstaal PJ. Anticoagulants versus antiplatelet therapy for preventing stroke in patients with nonrheumatic atrial fibrillation and a history of stroke or transient ischemic attack. Cochrane Database Syst Rev 2004;(4):CD000187.

9. Morocutti C, Amabile G, Fattapposta F, et al. Indobufen versus warfarin in the secondary prevention of major vascular events in nonrheumatic atrial fibrillation. SIFA (Studio Italiano Fibrillazione Atriale) Investigators. Stroke 1997;28:1015-21.

10. Connolly SJ, Pogue J, Hart R, et al. Clopidogrel plus aspirin versus oral anticolagulation for atrial fibrillation in the Atrial fibrillation clopidogrel trial with irbesartan for prevention of vascular events (ACTIVE W). Lancet 2006;367:1903-12.

11. Mant J, Hobbs FDR, Fletcher K, on behalf of the BAFTA investigators and the Midland Research Practices Network (MidReC). Warfarin versus aspirin for stroke prevention in an elderly community population with atrial fibrillation (the Birmingham Atrial Fibrillation Treatment of the Aged Study, BAFTA): a randomized controlled trial. Lancet 2007;370:493-503.

12. Palareti G, Leali N, Coccheri S, et al. Bleeding complications of oral anticolagulant treatment: an inceptioncohort, prospective collaborative study (ISCOAT). Italian Study on Complications of Oral Anticolagulant Therapy. Lancet 1996;348:423-8.

13. Glazer NL, Dublin S, Smith NL, et al. Newly detected atrial fibrillation and compliance with antithrombotic guidelines. Arch Intern Med 2007;167:246-52.

14. Di Pasquale G, Mathieu G, Maggioni AP, et al. Current presentation and management of 4148 patients with atrial fibrillation in cardiology and internal medicine hospital centres: The ATA AF study. Int J Cardiol 2012; 167:2895-903.

15. Schulman S, Beyth RJ, Kearon C, Levine MN. Hemor- 
rhagic complications of anticolagulant and thrombolytic treatment: American College of Chest Physician Evidence-Based Clinical Practice Guidelines (8th Edition). Chest 2008;133:257S-98S.

16. Palareti G, Cosmi B. Bleeding with anticoagulation therapy - who is at risk, and how best to identify such patients. Thromb Haemost 2009; 102:268-278.

17. vanWalraven C, Hart RG, Singer DE, et al. Oral anticolagulants vs aspirin in nonvalvular atrial fibrillation: an individual patient meta-analysis. JAMA 2002;288:2441-8.

18. Poli $\mathrm{D}$, Antonucci $\mathrm{E}$, Testa $\mathrm{S}$, et al. Bleeding risk in very old patients on vitamin $\mathrm{K}$ antagonist treatment: results of a prospective collaborative study on elderly patients followed by Italian Centres for Anticoagulation. Circulation 2011;124:824-9.

19. Agarwal, R Hachamovitch, V Menon. Current trial-associated outcomes with warfarin in prevention of stroke in patients with nonvalvular atrial fibrillation. Arch Intern Med 2012;172:623-31.

20. Smith EE, Rosand J, Knudsen KA, et al. Leukoaraiosis is associated with warfarin-related hemorrhage following ischemic stroke. Neurology 2000;59:193-7.

21. Iech S, Ebner T, Ludwig-Schwellinger E, et al. The metabolism and disposition of the oral direct thrombin inhibitor, dabigatran, in humans. Drug Metab Dispos 2008; 36:386-99.

22. Connolly SJ, Ezekowitz MD, Yusuf S, et al. Dabigatran versus warfarin in patients with atrial fibrillation. N Engl J Med 2009; 361:1139-51.

23. Diener HC, Connolly SJ, Ezekowitz MD, et al. Dabigatran compared with warfarin in patients with atrial fibrillation and previous transient ischemic attack or stroke: a subgroup analysis of RE-LYtrial. Lancet Neurol 2010;9:1157-63.

24. Wallentin L, Yusuf S, Ezekowitz MD, et al. Efficacy and safety of dabigatran compared with warfarin at different levels of international normalized ratio control for the stroke prevention in atrial fibrillation : an analysis of the RE-LY trial. Lancet 2010;376:975-83.

25. Eikelboom JW, Wallentin L, Connolly SJ, et al. Risk of bleeding with 2 doses of dabigatran compared with warfarin in older and younger patients with atrial fibrillation: an analysis of the Randomized Evaluation of Long-term Anticoagulant Therapy (RE-LY) trial. Circulation 2011;123:2363-72.

26. Hart RG, Diener H, Yang S, et al. Intracranial haemorrhage in atrial fibrillation patients during anticoagulation with warfarin or dabigatran: the RE-LY trial. Stroke 2012;43:1511-7.

27. Van Ryn J, Stangier J, Haertter S, et al. Dabigatranetexilate - a novel, reversible, oral direct thrombin inhibitor: interpretation of coagulation assays and reversal of anticoagulant activity. Thromb Haemost 2010;103:1116-27.

28. Zhou W, Schwarting S, Illanes S et al. Hemostatic therapy in experimental intracerebral hemorrhage associated with the direct thrombin inhibitor dabigatran. Stroke 2011;42:3594-9.

29. Huisman MV, Lip GY, Diener HC, et al. Dabigatranetexilate for stroke prevention in patients with atrial fibrillation: Resolving uncertainties in routine practice. Thromb Haemost 2012;107:838-47.

30. Connolly SJ, Ezekowitz MD, Yusuf S, et al. Newly iden- tified events in the RE-LY trial. N Engl J Med 2010;363: 1875-6.

31. Hohnloser SH, Oldgren J, Yang S, et al. Myocardial ischemic events in patients with atrial fibrillation treated with dabigatran or warfarin in the RE-LY (Randomized Evaluation of Long-term Anticoagulation Therapy) trial. Circulation 2012;125:669-76.

32. Uchino K, Hernandez AV. Dabigatran association with higher risk of acute coronary events: meta-analysis of noninferiority randomized controlled trials. Arch Intern Med 2012;172:397-402.

33. Connolly SJ, Wallentin L, Ezekowitz MD, et al. The long-term multi-center observational study of dabigatran treatment in patients with atrial fibrillation: (RELYABLE) study. Circulation 2013;16:237-43.

34. Larsen TB, Rasmussen LH, Skjoth F, et al. Efficacy and safety of dabigatranetexilate and warfarin in "realworld" patients with atrial fibrillation. JACC 2013;61: 2265-73.

35. Eikelboom JW, Weitz JI. New anticoagulants. Circulation 2010;121:1523-32.

36. Connolly SJ, Eikelboom J, Joyner C, et al. Apixaban in patients with atrial fibrillation. New Engl J Med 2011; 364:806-81.

37. Diener HC, Eikelboom J, Connolly SJ, et al. Apixaban versus aspirin in patients with atrial fibrillation and previous stroke or transient ischemic attack: a predefined subgroup analysis from AVERROES, a randomized trial. Lancet Neurol 2012;11:225-31.

38. Granger CB, Alexander JH, McMurray JJ, et al. Apixaban versus warfarin in patients with atrial fibrillation. $\mathrm{N}$ Engl J Med 2011;365:981-92.

39. Easton JD, Lopes RD, Bahit MC, et al. Apixaban compared with warfarin in patients with atrial fibrillation and previous stroke or transient ischemic attack: a subgroup analysis of the ARISTOTLE trial. Lancet Neurol 2012;11:503-11.

40. Abrams PJ, Emerson CR. Rivaroxaban: a novel, oral, direct factor Xa inhibitor. Pharmacotherapy 2009;29: 167-81.

41. Patel MR, MahaffeyKW, Garg J, et al. Rivaroxaban versus warfarin in non-valvular atrial fibrillation. $\mathrm{N}$ Eng $\mathrm{J}$ Med 2011;365:883-91.

42. Hankey GJ, Patel MR, Stevens SR, et al. Rivaroxaban compared with warfarin in patients with atrial fibrillation and previous stroke or transient ischaemic attack: a subgroup analysis of ROCKET AF. Lancet Neurol 2012;11:315-22.

43. Banerjee A, Lane DA, Torp-Pedersen C, Lip GYH. Net clinical benefit of new oral anticoagulants (dabigatran, rivaroxaban, apixaban) versus no treatment in a "real world" atrial fibrillation population: a modelling analysis based on a nationwide cohort study. Thromb Haemost 2012;107:584-9.

44. Ntaios G, Papavasileiou V, Diener HC, et al. Nonvitamin-K-antagonist oral anticoagulants in patients with atrial fibrillation and previous stroke or transient ischemic attack: a systematic review and meta-analysis of randomized controlled trials. Stroke 2012;43:3298-304.

45. Schneeweiss S, Gagne JJ, Patrick AR, et al. Comparative efficacy and safety of new oral anticoagulants in patients with atrial fibrillation. Circ Cardiovasc Qual Outcomes 2012;5:480-6. 
46. Rasmussen LH, Larsen TB, Graungaard T, et al. Primary and secondary prevention with new oral anticoagulant drugs for stroke prevention in atrial fibrillation: indirect comparison analysis. BMJ 2012;345:e7097.

47. Giugliano RP, Ruff CT, Rost NS, et al. Cerebrovascular events in 21105 patients with atrial fibrillation random- ized to edoxaban versus warfarin. Stroke 2014;45: 2372-8

48. Ruff CT, Giugliano RP, Braunwald E, et al. Comparison of thet efficacy and safety of new oral anticoagulants with warfarin in patients with atrial fibrillation: a metaanalysis of randomized trias. Lancet 2014;383:955-62. 